Portland State University

PDXScholar

1979

\title{
The interruption of the developmental tasks through pregnancy in the female adolescent
}

\author{
Suzanne Epstein \\ Portland State University \\ Kathleen Perkins \\ Portland State University
}

Follow this and additional works at: https://pdxscholar.library.pdx.edu/open_access_etds

Part of the Developmental Psychology Commons, and the Social Work Commons Let us know how access to this document benefits you.

\section{Recommended Citation}

Epstein, Suzanne and Perkins, Kathleen, "The interruption of the developmental tasks through pregnancy in the female adolescent" (1979). Dissertations and Theses. Paper 2781.

https://doi.org/10.15760/etd.2777

This Thesis is brought to you for free and open access. It has been accepted for inclusion in Dissertations and Theses by an authorized administrator of PDXScholar. Please contact us if we can make this document more accessible: pdxscholar@pdx.edu. 


\title{
THE INTERRUPTION OF THE DEVELOPMENTAL TASKS
}

\author{
THROUGH PREGNANCY IN THE
}

FEMALE ADOLESCENT

\section{by}

Suzanne Epstein

Kathleen Perkins

A practicum submitted in partial fulfillment of the requirements for the degree of

MASTER OF SOCIAL WORK

Portland State University

1979 
TO THE OFFICE OF GRADUATE STUDIES AND RESEARCH:

Jack R. Hegrenes, Ph.D., approves the practicum of Suzanne Epstein and Kathleen Perkins presented May 14, 1979.

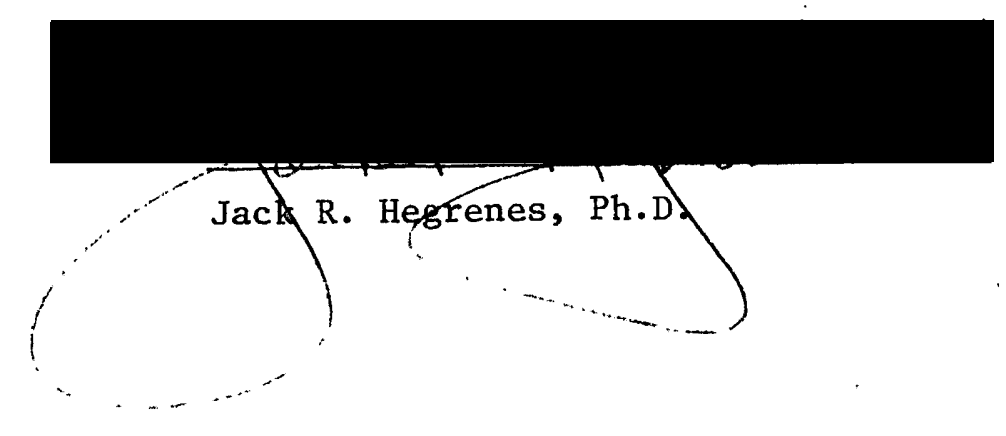

APPROVED :

Bernard Ross, Dean, School of Social Work 


\section{ACKNOWLEDGEMENT}

We would like to express our gratitude to Jack R. Hegrenes, Ph.D., Associate Professor of Social Work for his kindly assistance and inspiration. We would also like to extend our thanks and appreciation to the staff of the Teen Mother's Program for their cooperation in assisting us in the completion of this project. 
TABLE OF CONTENTS

PAGE

ACKNOWLEDGEMENT

iii

ABSTRACT

CHAPTER

I INTRODUCTION . . . . . . . . . . . . . . . . . 1

II REVIEW OF THE LITERATURE . . . . . . . . . . . . . . 2

III SETTING •. . . . . . . . . . . . . . . . 23

IV METHOD . . . . . . . . . . . . . . . . . 26

$\mathrm{V} \quad \mathrm{RESULTS}$. . . . . . . . . . . . . . . . . . 28

VI CONCLUSIONS • • • • • • • • • • • • • • • • 35

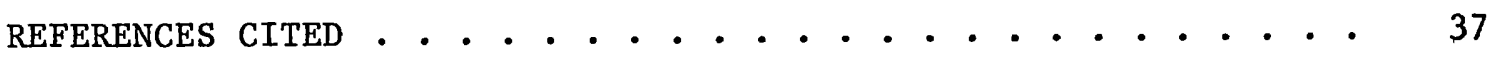

BIBLIOGRAPHY . . . . . . . . . . . . . . . . . . . . 40 


\section{ABSTRACT}

There is much information about the incidence of adolescent pregnancy yet little attention has been directed to how this process will interrupt the working towards or completion of the developmental tasks of adolescence. It is our belief that completion of these. tasks is crucial in relation to moving into the next stage, adulthood.

Public interest and concern for the contemporary needs of pregnant adolescents and school age parents as a special group is still fairly novel. Survey findings revealed that adolescent parents still have great need for infant day care services, direct financial assistance, housing arrangements, education, and parenting education.

In this study, a service provider to teenage adolescents who are pregnant, Salem Teen Mother's Program, was examined in depth to assess the components of their program which assist with working toward completion of the tasks.

Additionally, we looked at two cohorts of girls. Those that accepted and those that rejected the offered services at the Teen Mother's Program and developed a profile on each girl consisting of the following traits: age, marital status, religious preference, employment status, and race; the purpose being, to compare the two groups to see if there are reasons why they accept or reject participation in the program. 
Following completion of the profile, we then looked at the elements of the Teen Mother's Program and how they generally address the tasks.

The review of the literature examines why teens get pregnant, statistics on pregnancy, an explanation of how various programs have helped, and the medical risks associated with teenage pregnancy. A description of the Salem Teen Mother's Program is presented. 
CHAPTER 1

\section{INTRODUCTION}

This will be an exploratory and descriptive research practicum. Our intent is to look at the developmental tasks of adolescence and epitomize them into six categories. Although several different theoticians have defined the tasks in many ways, we have chosen to narrow them down to the following:

1. Development of an occupational identity/selection of occupation.

2. Develop capacity for mature and stable relationships outside of the family.

3. Character formation, develop integrated personality; sense of self; adaptive ego functioning, capacity to direct self into the future and more mature management of impulses.

4. Orientation towards future.

5. Achieving adult control, learning to make own decisions.

6. Determination of one's sexual identity.

We chose to conduct our research at the Salem Teen Mother's Program in Salem, Oregon to ascertain what kind of things can be done in a program that attends directly to helping the adolescent deal with completion of the tasks. 


\section{CHAPTER II}

REVIEW OF THE LITERATURE

Our review of the literature reveals: Faulty psychological development in the individual female can no longer be held as totally responsible for the existence of adolescent pregnancy. There is no certain knowledge as to characterological types, for we often come across the healthy young woman who becomes pregnant. In some cases, cultural norms may provide us with some clues. However, we are of the opinion that at the core of this phenomenon is both a blatant lack of adequate knowledge concerning birth control as well as a lack of resources from where these methods can be obtained.

It can not be overlooked that many of these young women are engaging in sexual intercourse for the basic purposes of being held or loved. There exists a profound need in many teens for the intimacy that might be lacking in the girl's immediate environment. Sexual fee1ings are reported as basically unimportant. The sexual act itself is described by teens as either disgusting or tolerable. We believe pregnancy is the undesired consequence of these sexual relations, sought not for the unconscious motives to procreate, but rather to establish some form of human contact and intimacy so desperately needed in many young women.

Evidence shows that the only traits these teenage girls have in common, besides their loss of virginity, is an incredible lack of 
knowledge about the reproductive process and birth control, and a fundamental lack of self esteem.

Additionally, adolescents in many rural communities feel there are no real family planning resources available to them. They may also be fearful of being seen or revealed as sexually active. Schools are ignored as sites for pregnancy prevention programs.

Lack of information concerning contraception shows up in the various myths and misconceptions about birth control; for example; the pill is effective when taken as needed like aspirin. Teens gather much misinformation about sex from their peer groups. The superstitions and distortions are passed from generation to generation, Godfrey Cobliner states in his article on "Pregnancy in the Single Adolescent Gir1", "There is almost no flow of information in this matter of sexual expertise from experienced to inexperienced adolescents, even if they happen to be friends or close relatives. The abundance of inexperience and easily obtainable books on. the subject matter makes no dent in the barrier to sexual enlightenment among single adolescents".

While there does exist a difficulty in making valid information available concerning contraception, another problem does exist. To admit a pregnancy risk is to admit forethought for sexual activity, Family doctors or mother's gynecologist are reminders of parental restrictions on sexuality. Turning to someone connected with childhood and/or parents may cause embarrassment in the area of sexual taboos,

Other girls may harbor strong religious beliefs, having been trained that birth control goes against the law of God. 
Further, the standards, ideals, and values of minority groups may act to facilitate or inhibit the wish for children. Radical blacks, for example, have adopted the point of view that use of birth control is a form of genocide. ${ }^{3}$

The absence of female use of contraception by the unmarried teenager is part of a tradition that sees male use as appropriate, considerate, and responsible, and female use as inappropriate and possibly immoral. ${ }^{4}$ This psuedomoral barrier results in the female. depending on the male for protection which, as is evident, will often lead to an undesired pregnancy.

Persons looking for information in this field are likely to become confused by the variety of statistics available on adolescent birth rates.

For example, one source states, "Despite a general decline in total births to all teenagers nationally, the proportion of teenage births increased from $17 \%$ in 1966 to $19 \%$ in 1975 . The birth rate to older teenagers (18-19) dropped substantia1ly; whereas, the birth rate for those 15-17 did not decline between 1966 and 1975 . Growth in this cohort led to a $22 \%$ increase in annual births to this age group. Nationwide, in 1975, 13,000 babies were born to adolescents under the age of $15^{\prime \prime} .5$

Another relates;". . births to teenagers now figure more prominently among al1 births up from 14\% of the total in 1960 to nearly one in five (1970) in 1974". 6

And still another source outlines the following statistics on teenage pregnancy: "In 1975 the number of females 10 to 19 nearly 
doubled. This accounts for the existence of 20.3 million females. The number of births to women of that age group increased 594,880. Births to females 10 to 14 years of age have nearly doubled. In 1957 there were 6,960 births to females age 10 to 14 . In 1975 there were $12,642.17$

Teen and preteen births are not confined to any one population area. They occur among young people of all ethnic and economic backgrounds. There are teenage and preteen parents living in suburban and rural areas as well as the inner city. The number of births to teens and preteens in non-metropolitan countries, those with populations below 50,000, showed the same one out of five ratio to all births in 1975.

From these figures we can conclude that there is not an alarming increase in the rate of teenage pregnancies. However, by virtue of the fact that the highest rates are now showing up among the very young, there can be no doubt that the issue is critical. While the public health aspects of the issue are fairly well documented, the long term implications for sociology, education, the job market, and other areas of interpersonal and intergenerational relations remain relatively uncharted.

Turning to this area, we will now discuss the tasks an adolescent must achieve in terms of the continuity hypothesis and the relation of the interruption of these tasks through pregnancy.

According to the continuity hypothesis, there are stages in development with each stage fitting and locking with the preceeding one. Each stage is the foundation for the next. Various tasks 
must be completed to provide this foundation. If the preceeding tasks involved in a stage of development are not satisfactorily completed, this will create various developmental problems. "A developmental task is a task which arises at or about a certain period in the life of the individual,' successful achievement of which leads to his/her happiness and success with later tasks, while failure leads to unhappiness in the individual, disapproval by the society, and difficulty by later tasks". 8

"Adolescence is a critical period that signals the end of the tranquility of childhood and heralds the onset of frustrations of early adulthood". 9

The most widely quoted source on psychosocial development is Erik Erikson. Erikson labels the developmental stage of adolescence as identity vs. role confusion. Adolescents are primarily concerned with what they appear to be in the eyes of others as compared to what they feel they are. For this reason there is a temporary overidentification with the heroes of the cliques and crowds. Out of this experience the adolescent must begin to settle on an occupational identity. However, occupational identity is only one facet of her general identity search. "Adolescent love is an attempt to arrive at a definition of one's identity by projecting one's diffused ego image on another and by seeing it thus reflected and gradually clarified". 10

The clannishness of the adolescent acts as a defense against the sense of identity confusion. Peers are able to temporarily help one another through much discomfort by banding together in small groups. Underlying the task of achieving an identity, according to Erikson, is the search for social values. 
Malony states, "Erikson has suggested that the prime concerns of adolescence could be construed as the search for identity and intimacy. The adolescent is trying to avoid being a nobody or becoming isolated and alone. She is seeking a place for herself among friends and in a vocation. She is yearning for the comfort of knowing where she is going. Later, there is an interest in intimacy, a relationship in which one can be oneself, give up one's roles, trust another, be open, honest, and share. The adolescent is attracted to and yet fears intimacy more than anything else in her life. If the adolescent is uncertain about her identity or has not yet decided what life role she will play, intimacy might mean a loss of self".

It is of interest to us that neither of these tasks, identity nor intimacy, are involved in parenting. This makes it easier to understand why the response of teens to adults teaching them to parent is so often negative.

Erikson suggests that parenting is, rather, a preoccupation of adulthood and not adolescence. It is only after an identity is secured and one has overcome one's feelings of isolation demonstrating that intimacy is attainable without loss of self, that an interest is activated in wanting to care for children. Turning one's interests outward is very difficult without the resolution of inner conflicts over identity and intimacy.

Havighurst lists the tasks of adolescence as follows: (1) Emotional independence from parents is established; (2) Boys and girls learn to be attractive to one another; (3) Adolescents learn to work together on common interests and to subordinate personal differences 
in pursuit of a common goal; (4) Vocational interests come to the fore; (5) Toward the end may come a time of altruism and reflection on problems of good and evil. He goes on to relate the basic psychosocial tasks. First, like Erikson's, is the achievement of identity. Second, is achieving new and more mature relations with age mates of both sexes. The goal here is to learn to look upon girls as women and boys as men; to learn to work with others for a common purpose, disregarding personal feelings; and to learn to lead without domineering. The biological basis for this is that sexual maturity is achieved and sex attraction becomes the dominant force in the individual's life. As a psychological basis, from the ages of 12-13 adolescents are preoccupied with social activities with the other sex in order to learn adult social skills. Accomplishment of this task makes for a reasonably good social adjustment throughout life and a good chance at other tasks. Failure can lead to an unhappy adult life with marriage being made difficult, impossible, or unhappy. Individuals in failing to learn to work. with other people as equals may be limited in later relationships to childish dependence or to arbitrary dominance.

Another psychosocial task outlined by Havighurst is achieving a masculine or feminine social role. The nature of this task is to accept and learn a socially approved adult feminine social role. Accepting one's physique and using the body effectively is another task. The goal here is to become proud or at least tolerant of one's body, to use and protect it effectively and with personal satisfaction. Endocrine changes provide the biological basis for this task as they aid in bringing on the development of adult sexual charac- 
teristics and physique. Adolescence is a time when one learns what her adult physique will be. Because of this, she is constantly comparing herself to her peers.

Havighurst also discusses achieving emotional independence from parents and other adults. The goal here is to become free from childish dependence on parents and at the same time develope an affection for them. Since the adolescent can't find sexual satisfaction within the family, she must go outside and establish emotional ties with people her own age. Psychologically speaking, the adolescent is ambivalent about this. She wants to grow up yet the adult world is strange and complicated causing her at times to yearn for parental protection. Yet, failure to achieve this task results in overly dependent adults who are often still tied to their parents, unable to make up their minds on important matters, and to move about freely in adult society because they are emotionally still children.

Preparing for marriage and family life as a task has as its goal developing a positive attitude toward family life and having children. It also involves obtaining the necessary knowledge for child rearing. The task of preparing for a career goal implies the adolescent must organize one's plans and energies in such a way as to begin in. an orderly career, or the planning of one, and to feel able to make a living.

Acquiring a set of values and an ethical system as a guide to behavior involves two elements; selection and preparation for a career of work or homemaking and the formation of a socio-ethical ideology 
Final1y, Havighurst describes the last task as deserving and achieving socially responsible behavior. Here, the goal is to develop a social ideology and to participate as a responsible adult in the life of the community. One implication is that to accomplish this final task the adolescent must take into account the values of society in her personal behavior. 12

Another source lists eight similar objectives that adolescents must seek to obtain: (1) General emotional maturity, (2) General social maturity, (3) Interest in the other sex, (4) Emancipation from home control, (5) Intellectual Maturity, (6) Selection of an occupation, (7) Appropriate uses of leisure, (8) Philosophy of 1ife. ${ }^{13}$

Hegrenes defines the tasks of adolescence as: (1) Emancipation (developing the ability to handle one's own life and support oneself financially), (2) Formation of sexual identifications (heterosexual maturation), (3) Develop capacity for mature and stable relationships outside the family, (4) Character formation (develop integrated personality, sense of self), adaptive ego functioning (capacity to direct self into the future), and mature management of impulses (consistent internalized super ego), (5) Develop an orientation toward the future (ability to make realistic plans).

Wattenberg 1ists as major tasks: (1) Independence in one form or another must be achieved, (2) Place must be found for relationships with the opposite sex, (3) Must master skills, social and vocational, that will enable her to function as a full-fledged member of society, (4) Achieving adult control (learning to make own decisions), leaning less on parents and other grown ups, developing new skills. (developing competence in new roles), and new ideas of self. Involved is an estimate 
of her attractiveness, intelligence, and interests. It also includes feelings of inferiority, worthness, confidence, and belonging to groups. The result is a formation of a realistic and attainable inner sense of who she 1s. ${ }^{14}$

Oberst defines the tasks as: (1) Arrive at becoming a distinctly mature individual and to assume her ultimate role in the community, individually and collectively, (2) Needs to develop own comprehension in a number of areas in relationship to own self image--an understanding of her own convictions, an insight into her own feelings, a need to develop her own sense of values, and a comprehension of what is right and wrong within her own self toward her socialization in society, (3) Has to involve a number of different types of beliefs, moral belief and a belief in the universe. She begins to involve ideas concerning the occupation she may wish to pursue. 15

Developmental tasks, according to LaBarre, have been delineated as: (1) Completion of biological maturity, (2) Development of self identity, (3) Determination of one's sexual identity, (4) Development of capacity for lasting relationships and for both tender and genital sexual love in a heterosexual relationship, (5) The attainment of independence and separation from one's parents, (6) The development of a personal value system, (7) The choice of a vocation and commitment to work. 16

It would appear from the review of the literature that the basic task is to replace the dependent childhood attachment to one's parents with a mature adult relationship to them and others. This involves the establishment of intimate relationships with others, including a sexual 
adaptation. 17 Establishment of a sense of identity, then, is the central problem of adolescence.

Along with the psychosocial task of adolescence are the cognitive tasks that need to be completed as outlined by Piaget. Adolescence is the period of formal operations or abstract thinking. It is the ability to make logical deductions from imagined conditions. Cognitive competence brings about: (1) Increased sense of control over one's environment, (2) Capacity to defer immediate or later gratification, (3) Skills in working cooperatively with others, (4) Patterns of socially responsible behavior, (5) Techniques for nondestructive resolution of personal and interpersonal problems. (Hegrenes)

In early adolescence, the child acquires the capacity to perform operations on operations. An adolescent will apply logical operations to systems of thought as well as to concrete situations. "This reflection provides the basis for seeing the real as just one of many possibilities and for the forming of scientific hypotheses."18

The formal operations stage which begins at around 11 or 12 years of age is characterized by a stable system of abstract thought structures by about 14 to 15 years of age. The adolescent is not bound by immediate reality. She can follow the form of an argument, can consider different hypotheses, and can contemplate what might follow. "The adolescent is beginning to think of the future, to plan her present and future work, and to anticipate the ways in which she would like to see the world changed so that it could help her realize her ambitions. At the same time, she is beginning to view herself as an adult and to develop expectations about reciprocal interactions with adults. According to 
Piaget, the logic of formal operations is the expression of operational coordinations essential to action; hence, cognitive structural development and adaptation to everyday life are on the plane of reality."19 The Piagetian system recognizes the adolescent can conceive of ideal families, religions, and societies. She can construct ideals, can reason contrary to fact propositions through to conclusions, and can compare her ideals with her own family, religion, and society.

Cognitive growth requires the adolescent to continue the decentering process. She must learn to distinguish between what she herself would like to be and what the expectations of others are, both for themselves and her.

The adolescent can now see cause and effect in a clear way and consequences for actions ahead of time, She is developing the ability to plan.

With the arrival of formal operations she begins to see her parents differently; perceiving them the way they really are with their faults and weaknesses. However, just because the adolescent can see cause and effect, intellectually it doesn't mean she has any control. ${ }^{20}$

"Recent research on cognitive theory reveals wide differences in timing of the shift from concrete operations or ability to reason on the basis of objects which is characteristic of childhood, to formal operations or the ability to reason on basis of abstractions or symbols which is even more characteristic of adulthood."21 It may begin in some at 11 , in others not until 20 , in some not at all.

We can conclude that ". . many young girls become pregnant because, in part at least, their personal fable convinces them that 
pregnancy will happen to others but never to them and so they need not take precautions." 22

Furthermore, if we use Piaget's framework, we can better understand how the accident view of pregnancy makes sense to an adolescent if she doesn't know the physical facts about pregnancy or if she has the facts, but doesn't know what they mean.

When a young woman becomes pregnant, she experiences profound physiological and psychological transformations. The tasks that accompany these changes are often in conflict with those that accompany the stage of adolescence. Earlier psychological conflicts may erupt which for their resolution, require new methods of coping. Mastery of this conflict will depend on how this new crisis is dealt with, Once a teenager becomes pregnant, she must go forth; unable to return to the earlier stage of childhood. 23

LaBarre states, "In some cases the discovery of the pregnancy precipitates an acute crisis episode of shock, stress, and anxiety; disrupting the previous adjustment and requiring the reorganization or development of new coping methods to deal with the trauma." 24

Perhaps two of the most important tasks that are interrupted through pregnancy are those of establishing a stable self image and separating from the family of origin. In the former case, the physical changes related to pregnancy interrupt the development of a stable body image. This is highly significant to the adolescent who is very body oriented. Additionally, pregnancy may prevent the young woman from keeping up with active peers. Access to the peer group/friends is important in establishing a satisfactory self image. 
Teenagers who must remain physically dependent on parents due to pregnancy have heightened guilt and conflict about the negative feelings they harbor against their parent(s). Consequently, they may become openly defiant. Adolescence is the period when the self image coalesces. The personality is particularly open and vulnerable to experiences of every kind. Enforced dependence on parents generally results in heightened conflict as this is the psychological period when she should be liberating herself.

Hobart states, "In many cases the pregnancy triggers a certain amount of rejection of the girl by her parents (and perhaps her parentsin-law) since it has caused conment among friends and relatives and has perhaps brought a certain amount of notoriety, if not of scandal, to the families involved." 25

The pregnancy serves very seriously to disrupt the relations of the girl with her peers. If it is an unwed pregnancy, the girl is often snubbed or even ostracized by her friends. "In all cases, the pregnancy tends to prevent her from continuing in common pursuit and activities with them and it invests her with a new set of hopes, fears, anxieties, and interests widely at variance with those of her friends."26

Thus, it becomes apparent that the sociological consequences of pregnancy for the high school girl is a radical and thorough alienation of the girl from virtually all of the reference groups which had made her life satisfying and meaningful.

The inevitable consequences of this alienation of the girl from virtually all of the social relationships which had given her life support, significance, and meaning, is a demoralization of the girl's 
life. In numbers of ways, it may tend to go to pieces under impact of a crisis which tends to sweep away the major sources of support which could help weather her through the crisis. The consequences of this sequence are frequently in terms of human misery of the girl, her mother, and others. They are also wasteful and costly. If the girl is not enabled to reorient herself successfully, to persevere and graduate from high school and perhaps to go on to college or on to technical school, she will fail to develop her full potential. In consequence; she may be forced to live a needlessly shallow life. Her family and her community will be denied the benefit of the skills she would have learned and her country will have been impoverished in that some of the human resources potential in the girl were wasted, 27

Grinder also sees isolation from peers as a crucial interruption. He relates, "An unwed pregnancy usually denies a girl access to the social relationships that have made her life meaningful and significant. Her changing physical appearance may isolate her and make her lonely. The girl is unable to participate in activities with her friends."28

The girl's family, friends, and other social groups have provided her with acceptance, status, and popularity; but pregnancy has altered her pattern of relationships with them.

Without acceptance by a peer group, the adolescent feels a deep and morbid sense of insecurity and unhappiness and a sense of not belonging anywhere.

The girl who is attempting to free herself from family dependency must now submit herself to her parents for help.

The girl who becomes pregnant in her teens has not yet fulfilled her female adolescent maturational functions. She is also attempting 
to reach educational goals and is often in the process of making yocational choices and establishing life goals. According to Shouse, when pregnancy occurs during adolescence, the typical ambivalent strivings. for emancipation and self dependence are both reflected and disrupted. The girl is in the process of separating from her parents yet the pregnancy can make her regressive and dependent. A strong ambivalence may also develop about leaving the family due to problems relating to financial support which evoke both anxiety and angex. 29

In addition to the numerous problems of adolescence, these girls face major educational and social problems. Educational difficulties frequently precede adolescent pregnancy, and once pregnant, girls tend to drop out of school permanently. 30

Another major concern is the interruption of the school process. "Title IX of the Education Amendments of 1972 (effective July 12, 1975) prohibits schools which receive federal funds from excluding any student on the basis of pregnancy or a pregnancy related condition. Even so, the extent to which young women stay in school during pregnancy or are able to retum after a birth varies widely. The demands of child care may make it difficult for some new mothers to remain in school even if they are not barred by school policy." 31

The girl who bears a child while still an adolescent is likely to both interrupt her school and make it difficult to find work because of her child care responsibilities.

Cromwell and Gangel relate that pregnancy is the major known cause of school dropouts in the United States. The younger the girl, the less likely it is she will finish high school. 32 
Osofsky, et. al., also addresses the school dropout problem. Pregnant teens have a considerably worsened educational prognosis than teens in general. "In many areas of the U.S., pregnancy has been the number one condition resulting in teenage girls leaving school prior to graduation." 133

According to Ewer and Gibbs, "Once she has dropped out, the chances of the adolescent mother's returning to continue her education have been reported to be relatively small. This has been especially true for the girl who keeps her baby." 34

Fielding views the lost educational opportunity as one of the three most serious concomitants of adolescent pregnancy (in addition to unstable family life and poor employability). "Eight out of ten who become mothers at 17 or younger do not complete high school and four out of ten who have a child by age 15 do not finish eighth grade." 35

The sudden loss of the major role and occupation of adolescents, that of student, constitutes a real rejection and punishment of the pregnant girl. The frustration of hopes and plans and loss of self esteem may prove overwhelming. Also, there is always the constant fear that other students are suspecting or remarking on their pregnancy.

Closely related to the interruption of the school process are the vocational difficulties that follow. For this reason, the young childbearing woman has found difficulty achieving economic independence and employment. The opportunities are limited.

Results of Pollack's study show that 12 th grade pregnant girls attain lower vocational maturity than nonpregnant female 12 th grade students, Career choices were significantly less stable than those of the nonpregnant girls. 36 
Due to the above, the teenage girl is unlikely to obtain a job or even the social skills needed for employment; and therefore, she often becomes dependent on public welfare.

Gordon depicts the situation as follows, "Adolescence is a period in which the young girl is anxiously seeking the answers to the question of who she is. This search for identity is 1ikely to be accompanied by uncertainty and emottonal stress. If her uncertainty is suddenly intensified by the discovery that she is pregnant, it is only to be expected that in many cases she will enter into a psychological crisis." 37

There are many other social problems that accompany early childbearing. A few mentioned in the literature are early marriage and divorce rates, repeated early pregnancy, welfare dependency, and low social mobility. Divorce, according. to Osofsky et. al., occurs three to four times more frequently than among couples married at a later age. $^{38}$

Various programs around the country are beginning to address themselves to dealing with the previously mentioned problems that result in the interruption of the tasks of adolescence.

Comprehensive programs generally have the following goals: (1) To increase chances of a normal pregnancy and childbirth and to protect the health of mother and infant, (2) To help girls solve personal problems that may have led to pregnancy or resulted from it and to direct them towards a satisfying future, (3) To help girls keep up studies during pregnancy and to increase the proportion of girls who will continue in schooling after childbirth. 39 
Ryan and Sharpe describe the following ways in which a program should help the adolescent resolve the basic tasks: (1) Provide uninterrupted education or vocational opportunities for each individual, (2) Provide quality prenatal and postnatal care for mother and baby, (3) Provide assistance with practical problems surrounding pregnancy in psychological; social, and environmental aspects important to the client and her family. 40

Clark agrees that teens must have satisfying relationships with others. Programs should also deal directly with decreasing feelings of being abandoned and with maintaining self esteem. ${ }^{41}$

The educational component is equally important, The structure and requirements of the educational process are essential to and supportive of ego development in adolescence. A major advantage of attending a special school for pregnant girls is an opportunity to belong to a peer group.

Group sessions have also proved to be of extreme value in this area. The groups should be designed to stimulate intense and open avenues of communication. Girls in the group provide a substitute for the loss of a supportive peer group, as these young women are all basically facing the same situation.

A program conducted by the Department of Gynecology and Obstetrics of the Emory University School of Medicine in cooperation with the Atlanta Board of Education provided comprehensive services to pregnant adolescents. One group of students remained in usual classes for the duration. of the pregnancy and returned to school quickly after delivery as opposed to another group not allowed to remain in school. The 
results showed that the former group had higher rates of day school return. The program succeeded in promoting day school return primarily by eliminating barriers to that return so that the subjects high level of motivation to continue school could be realized. This was done by informing nearly all eligible students and their families to the opportunity to continue day school and encouraging them to do so. 42

The Young Mothers Educational Development Program in Syracuse and Onondaga Counties in New York make an effort to provide mothers and infants with the maximum opportunities to lead useful, productive lives within society. This program's results demonstrated, "That given a reasonable opportunity, individuals who are high risk and who are supposedly uninterested will respond. Medical complications, prematurity, and even perinatal mortality will be considerably reduced. In spite of a significant incidence of prior school problems, individuals will make considerable educational progress and will aim tor further achievement. Where sex education and contraception are available, the incidence of unwanted repeated pregnancies will be strikingly reduced."43

Programs need to address themselves to the fundumental tasks and needs of the adolescent. Adolescents are still struggling to accept responsibility for their own sexuality. Programs need to maximize preventative care and use peer group interaction to lower obstetric risk and decrease management problems. Good general health education is indicated to improve the chances at a successful family life and to pave the way for taking on the numerous responsibilities of adulthood. In a report prepared by the National Alliance Concerned with SchoolAge Parents, they state that, "Public interest and concern for contemporary needs of pregnant adolescents and school-age parents as a special 
group is still fairly novel. Only in the late $1960^{\prime}$ 's through a movement to establish a multidisciplinary intervention approach were pregnant adolescents and school-age parents singled out for attention because of their compelling need for a variety of human services. By 1973 there were an estimated 250 special programs for pregnant adolescents and young parents. In its 1976 National Directory of Services for School-Age Parents, it lists information of 1,134 agencies providing some type of specialized assistance to young people who are pregnant, who are parents, or who are sexually active. The introduction to the publication indicates a constant state of change among persons and services listed, noting that such services are often considered "frills" rather than essential. Survey findings revealed that adolescent parents still have great need for infant day care services, direct financial assistance, housing arrangements, and parenting education. School-age parent services are rarely considered a priority; but rather, included in agency programs designed to meet the need of other interest groups. "44 
CHAPTER III

SETTING

The Salem Teen Mother Program was started in March, 1967 to deal with some of the consequences related to the pregnancy of young women. In the beginning, services were limited and the number of participants were small. By October, 1968, the Teen Mother Program was serving 20 young women.

The present program is a comprehensive community-based program offering young mothers and pregnant young women educational, parenting, day care, job finding, health, and social services. The program, which is housed at the YWCA, receives community support from the Salem School District, State of Oregon Children's Services Division, Marion County Mental Health Department, Marion County Public Health Department, City of Salem Revenue Sharing, Community Coordinated Child Care (4-C's), Manpower Consortium, and local churches and services organizations. The overall goals of the program are to decrease the risks for the school-age mother and her child, and to help the young woman develop into a socially mature and economically self-sufficient person.' In order to accomplish these goals, efforts are made: (1) To increase the chances of normal pregnancy and childbirth, (2) To protect the health of both mother and child, (3) To help the young woman solve the personal problems that may have led to or resulted from the pregnancy, (4) To improve the young woman's self concept, (5) To help the young woman keep 
up her studies during pregnancy and to increase the proportion who will continue in school following childbirth, (6) To decrease the number of second unplanned pregnancies.

Since its inception, the Teen Mother Program has served approximately 1000 young women. At the present time, a monthly average of 75 young women are enrolled in the Teen Mother Program. An additional 30-35 young women per month who chose not to be in the YwCA program or are over 18 are served by the Outreach program.

For those young women in the Salem School District, two vans stop by their homes and pick up the young mothers and their babies and bring them to the YWCA. When it is more convenient for the young women to use the city bus, tickets purchased at a special social service rate are given them to use.

Special transportation is provided by staff and volunteers to get young women to medical, welfare, Children's Services, and other appointments that are necessary to meet the goals of the young women and the Teen Mother Program.

Referrals from doctors, counselors, and other agencies account for many of the young women who come to Teen Mothers. But the most frequent source of referral is word of mouth from young women in the program or past participants. The interrelationship of services within the program also attracts young women. Some come for school credit, some for prenatal needs, some for parenting and/or day care, some for job finding, some for socializing, and some for help with family, personal, or agency problems. The Teen Mother Program can help with all these areas and usually the young women become interested in the 
entire program. Since September, 1977, young women have to meet individual contract requirements to be in the program. They have nine weeks to become involved with educational classes, counseling groups, and health classes. If they do not meet these minimum requirements, they are put on probation and have to meet the requirements by the end of the second nine weeks or be placed on time out. Time out bars the student from all school activities, except by invitation by a staff member. 
CHAPTER IV

METHOD

Referrals to Teen Mothers are initially made by pubilc health nurses, doctors, school counselors, and other agencies. Additionally, as part of the outreach work done by the agency, all adolescent females delivering a baby at the Salem General Hospital are sent a letter from Teen Mothers describing community resources for school-age parents. One of the resources listed is the Teen Mother's Program. A telephone number is provided and contact is encouraged.

In order to develop profiles on the two cohorts of girls, those who accepted and those who rejected services, it was necessary that we examine two different forms on file at Teen Mothers. Information was obtained from the hospital discharge forms and was on file at Teen. Mothers which provided us with some basic facts on the cohort of girls who had been contacted and refused services. Identical information on the girls who had accepted services and were enrolled in the program for the academic year, 1978-79, was obtained from the Intake Forms also on file at Teen Mothers.

These forms provided us with the following information from which we were able to develop our profile of each cohort: race, age, marital status, religion, and employment status. We were able to secure this information on seventy females who did not utilize the services and on seventy females who elected to participate in the program. 
Interviews with several staff members were conducted for the purpose of obtaining information on the different components of the program and the manner in which these could be related to the completion of the six developmental tasks. 


\title{
CHAPTER V
}

\author{
RESULTS
}

From the profiles developed on the two cohorts of girls, those who had accepted and those who had rejected, we found the following differences.

The mean age for the cohort of girls who participated in the program is $17.6, \mathrm{SD}=1.2$. The mean age for the cohort of girls who did not participate in the program is $16.8, \mathrm{SD}=1.1$.

The percentage of girls employed in the cohort of girls who participated in the program is 3.6. The percentage of girls employed in the cohort of girls who did not participate in the program is 1.0 . The percentage of caucasion girls in the participant group is 99.9; .1 is black. The percentage of caucasion girls in the nonparticipant group is 100.

The percentage of girls with no religion in the cohort who participated is 50 . The percentage of Catholics is 5 . The percentage of Protestants is 45 . The percentage of girls with no religion in the cohort who did not participate is 25 . The percentage of Catholics is 6. The percentage of Protestants is 69.

The percentage of girls who are married in the cohort who participated in the program is 5.8. The percentage who are married in the cohort who did not participate in the program is 2.5 . 
Questions painfully asked by adolescents are, "Who am I?", "Where do I fit?", "Where am I going?". These are all related to the tasks of developing a sense of self.

Teen Mothers is a cooperative, community program which provides special services to the pregnant adolescents and school age mothers. In various ways, all components of the program address the six major tasks of adolescence. The components include the services of junior high and high school credit classes which help a young woman to continue her education; Public Health nurses who concentrate on prenatal health, postnatal health, and early childhood health and development problems; social services to the young women, parents, and young men involved in the program; child care for eligible young women; and employment services for teen mothers.

The pre-parenting component of Teen Mothers, perhaps more than any other, is where the major focus is placed in assisting teen mothers through the tasks. Three primary goals of the pre-parenting program is to: 1) Provide practice in clarification of values and effective and responsible decision making as preparation for parenthood, 2) Clarify and strengthen self image; the children provide an open and non-threatening media for the illumination and disscussion of self development, 3) Introduce realistic expectations through dealing directly with children and with concepts which promote mental as we11 as physical well being. The pre-parenting training is carried out around a core emphasis on personal clarification responsibility and decision-making skills. 
Much of the time spent in the class is based on experiential learning. A nursery with pre-school children (6 weeks to 5 years) provides a natural setting for this type of experience which students work at two times a week. The remaining three days per week are spent attending class. Role playing, simulation, fantasy, and values clarification are all a part of the classes. Topics covered are play, discipline, feelings, needs, self concept, self disclosure, acceptance, communication, values clarification, and constructive change.

This approach is a non-traditional one in relation to most parenting classes. Traditionally, parenting classes are taught with the assumption that if you know enough about children, you will be a good parent. The non-traditional approach says it takes healthy parents to raise healthy children. Underlying this approach is the assumption that it is not so important to know about yourself. You are unable to focus on a child until one takes care of their own needs. The use of the two adult co-leaders as role models assist the girls in getting away from the idea of an adult being foreign to them. Many of these girls have become accustomed to being focused on as children versus individuals by the significant adults in their lives.

One of the co-leaders of the group is a male, which may in the long run prove advantageous in assisting these girls with the opposite sex related tasks. Frequently there is not a man around the home for these girls to develop a suitable image. Most are either from broken homes or blended families. Approximately 60 to 70 percent are from single parent families. 
Developing one's identity is a direct result from having a feeling for who you are as a person. The majority of teens upon entering the program suffer from an extremely poor self concept. They tend not to spend as much time thinking about whether or not they are important enough as people to be future oriented.

The group experience provides them with a milieu in which they can experience hearing others talk about what they have experienced, what their families are like. This lessens the strangeness of their own experience and encourages them to share, get comfortable, and trust. From the group, the girls will often break down into dyads and triads. They are encouraged to be around someone they don't know so well. This helps force them out of their cliques. It has been the experience of the co-leaders that the level of trust has gone up dramatically following these type of exercises. Openness to others is stressed. Exercises are participated in to create self awareness. The girls are encouraged in every component of the program to make their own decisions after being provided with the necessary information. The counselors do not function in a parenting role. The emphasis appears to be that in order to make decisions they need to know themselves better. Once they are able to trust in themselves and provide for their own needs, they are better able to fulfill the parenting role.

Within the career counseling component, a work coordinator is available to all of the girls enrolled in the program as well as other school age parents in the tri-county area. Services include job counseling referrals and supportive services related to employment. 
Each student is assisted by the work coordinator in developing a complete resume through individual conferences or workshops. Certain types of employment can result in class credit or in meeting the competency requirements for high school graduation.

Coed social activities in the evening include volleyball, swimming, dining at local restaurants, skate parties, potluck dinners, and dances.

During the school year, field trips may vary from a day at the beach to a trip to old town in Portland. Activities such as health class, child development, field trips, and crafts also extend into the summer. Transportation and child care can usually be arranged.

The YWCA infant center makes day care available for the infants and toddlers of qualified teen mothers. Mothers and staff consult together about each child's development and the care received and set developmental goals. A Public Health nurse is involved with the day care center and is available to confer with parents. The opportunity is provided for mothers to make contact both with their children and the care givers during the course of the school day. As mentioned earlier in the description of the pre-parenting program, teen mothers are assigned work in the infant center as a part of their experience in the program.

The educational component provides an opportunity for these young women to continue their education during pregnancy and after childbirth in a specially designed supportive program. Junior high and senior high school classes which meet Salem public school requirements for a high school diploma are offered Monday through Friday from 
9:00 a.m. to 2:30 p.m. The Salem School District provides transportation to and from school, as well as breakfast and lunch for qualified students. Some home tutoring and special programs can be arranged to meet individual needs. The girls set up their own contracts on what they will do in school. The program has adopted a non-parental attitude in this respect. Rather, they state, if you complete the work, you will obtain the credit. Essentially, they are responsible for establishing their own direction.

The health services component aims to help young women work toward the advantages of a healthy pregnancy, prepared childbirth, and a healthy infant. Instruction is made available by a Public Health nurse in prenatal health, hospital procedure with a tour, childbirth, films and discussion, family planning, family health, child development, and first aid. School credit is applied for participation in these classes. The Health Department, through the Teen. Mother's Program, provides well-child medical appointments for babies which include immunizations, examinations, and consultation with a physician. A special opportunity for pregnant young women is the W.I.C. food coupon program which assists the teen not only during pregnancy, but also while nursing; and for her child by providing for a high protein diet. Family Planning Clinic services are made available through classes, private consultation, and access to Marion County Health Department.

The social service component provides counseling and coordinates the program services on an individual basis. A plan is developed for each girl to meet her needs and fulfill the requirements of the program. 
At least two individual sessions are offered as a means to meet the latter objectives. Meetings are also conducted within the last two weeks of each quarter to evaluate each girl's plans and accomplishments and to plan for the next quarter. Attendance at group sessions is also required for nine weeks per year. 


\section{CHAPTER VI}

\section{CONCLUSION}

It is the authors belief that working towards the completion of the developmental tasks of adolescence is crucial to coming into adulthood. As Havighurst has pointed out, failure in completion may lead to various problems later in life; among them, marriage being made difficult, impossible, or unhappy; being limited in later relationships to childish dependence or arbitrary dominance; an inability to make important decisions without depending on others; and the inability to move about freely in adult society because they are emotionally still children. 45

The opportunity to work through the six major developmental tasks, development of an occupational identity-selection of an occupation, developing a capacity for mature and stable relationships outside the family; character formation, developing an integrated personality, sense of self; adaptive ego functioning, capacity to direct self into the future and more mature management of impulses; orientation toward the future; achieving adult control, learning to make one's own decisions; and determination of one's sexual identity, is made available in the various components of the Teen Mother's Program. We have found the interruption of these tasks by pregnancy is not an inevitable process with the assistance of programs of this sort. 
The pre-parenting class, career counseling, social activities, infant day care, educational classes, health service, and the social service component combine to produce a conducive environment for the work to be done toward achieving completion of the tasks.

We did find the program to be lacking in its orientation to the young men who have parented the children. There is little information on the male counterpart of the young women. The Teen Mother's Program staff that we interviewed expressed interest in providing services to the young fathers but stated that often times the father's identity is unknown, or the female is unwilling to disclose who the father is, or the males simply do not express a burning desire to become involved. in the program. It would be interesting and beneficial for future research to be executed in this yet uncharted territory.

Based upon the established profiles of the two cohorts of girls, those who accepted and those who rejected the program, we were able to discern a noticeable difference. Though there is a difference, time did not allow us to determine the underlying causes. Therefore, future researchers will need to determine why certain types of girls are rejecting such programs.

Although upon completion of this study we are unable to conclude the developmental tasks are being addressed, we have, at this time, no way of ascertaining the long range effects of this program on the adolescent mothers as they enter adulthood. Again, we believe that it would be advantagious to complete a ten year follow-up/longitudinal study to verify how this program has contributed in the completion of these tasks. 
1. Gordon, So1. The Sexual Adolescent. Duxbury Press, Scituate, Mass., 1973, p. 37.

2. Cobliner, Godfrey. "Pregnancy in the Single Adolescent Girl: The Role of Cognitive Functions", Journal of Youth and Adolescence. Vo1. 3, No. 1, 1974, p. 17.

3. Tighe, Patti. "A Social Psychiatry View of Female Adolescent Contraception", The Teenage Pregnant Girl. Brandstadt, W. and Zackler, J. (editors). Charles C. Thomas, Springfield, II1., 1975.

4. Cutright, Philip. "Teen Age Illegitimacy: The Prospect for Deliberate Change", Ibid.

5. Fielding, Jonathan E. "Adolescent Pregnancy Revisited", Fielding, J. and Russo, Peal (editors), unpublished article, p. 1.

6. Baldwin, Wendy. "Adolescent Pregnancy and Childbearing--Growing Concerns for Americans", Population Bulletin. Vol. 31, No. 2, September 1976, p. 26.

7. Report by National Alliance Concerned with School Age Parents. "School Age Pregnancy and Parenthood in the United States", 1977.

8. Havighurst, Robert J. Developmental Tasks and Education. David McKay Co. Inc., New York, 1973, p. 12.

9. Lamers, William M. and Semmers, James P. Teen Age Pregnancy. Charles C. Thomas, Springfield, IIl., 1968, p. 5.

10. Erikson, Erik. Childhood and Society. W.W. Norton and Co. Inc., New York, 1963, p. 262.

11. Malony, H. Newton. "Can Adolescents be Taught to Parent?" Adolescence. Vo1. 13, No. 49, Spring 1978, p. 123.

12. Havighurst, Robert J. Developmental Tasks and Education.

13. Cole, Luella. Psychology of Adolescence. Farrar and Rinehart, New York, 1942.

14. Wattenberg, William W. The Adolescent Years. Harcourt, Brace, and World Inc., New York, 1955. 
15. Oberst, Byron B. "Adolescents and Some of Their Social Problems", SMJ Nebraska. September 1970.

16. La Barre, Maurine. "Emotional Crisis of Schoo1 Age Girls During Pregnancy and Early Motherhood", Journal of the American Academy of Child Psychiatry. Vol. 11, No. 1, January 1972.

17. Shouse, Judith W. "Psychological and Emotional Problems of Pregnancy in Adolescence", The Teenage Pregnant Gir1. 1975.

18. Grinder, Robert E. Adolescence. John Wiley and Sons Inc., New York, 1973, p. 195.

19. Ibid. p. 206 .

20. Muuss, Rolf E. "Jean Piaget's Cognitive Theory of Adolescent Development", Adolescence. Vol. 2, 1967, p. 299.

21. Schoo1 Age Pregnancy and Parenthood in the United States. 1977, p. 4 .

22. E1kind, David. "Egocentrism in Adolescence", Child Development. Vo1. 38, 1967, p. 1032 .

23. Bibring, Grete L., Dwyer, Thomas F., Huntington, S., and Valenstein, Arthur F. "A Study of the Psychological Process in Pregnancy and of the Earliest Mother Child Relationship", The Psychoanalytic Study of the Child. Vol. 16, 1961 .

24. Le Barre, 1972, p. 537.

25. Hobart, Charles W. "The Pregnant High School Girl: An Analysis and a Proposa1", Personnel and Guidance Journa1. Vo1. 40, September-May 1961-62, p. 787 .

26. Ibid. p. 788 .

27. Ibid.

28. Grinder, 1973, p. 314 .

29. Shouse, Judith. 1975.

30. McAnarney, Elizabeth R. "Adolescent Pregnancy--A Pediatric Concern", Clinical Pediatrics. Vol. 14, No. 1, January 1975.

31. Baldwin, 1976, p. 26. 
32. Cromwe11, Ronald E. and Gange1, Joan L. "A Social Action Program Directed to Single Parent Girls and Adolescent Parents", Family Coordinator. Vo1. 23, No. 1, January 1974.

33. Osofsky, Howard, Kenda11, Joy, Renga, Norman. "Adolescents As Mothers: An Interdisciplinary Approach to a Complex Problem", Journal of Youth and Adolescence. No. 2, September 1973 , p. 235 .

34. Ewer, Phyllis and Gibbs, James. "School Return Among Pregnant Adolescents", Journal of Youth and Adolescence. Vo1. 5, No. $2,1976, \mathrm{p} .221$.

35. Fielding, op. cit., p. 3 .

36. Pollack, Ronald I. "An Examination of Selected Vocational Behaviors of 12th Grade School Age Pregnant Girls", Dissertations Abstracts Internationa1. Vo1. 37, May 1977.

37. Gordon, Sol. 1973, p. 37.

38. Osofsky, 1973.

39. Gordon, 1973.

40. Ryan, Lee and Sharpe, Ruth. "A Comprehensive Service Program for School Age Pregnant Girls", The Teenage Pregnant Gir1. 1975.

41. Clark, Ann. "The Crisis of Adolescent Unwed Motherhood", American Journal of Nursing. Vol. 67, No. 7, July 1967.

42. Ewer and Gibbs. 1976.

43. Osofsky, 1973, p. 244.

44. Report by NACSAP. 1977, p. iii.

45. Havinghurst, 1973. 


\section{BIBLIOGRAPHY}

Clark, Ann. "The Crisis of Adolescent Unwed Motherhood", American Journal of Nursing. Vol. 67, No. 7, July 1967.

Hegrenes, Jack R., Ph.D. Conversation and class notes. 1979.

Midcentury White House Conference on Children and Youth. "The Course of Health Personality Development", The Adolescent--A Book of Readings. Dryden Press, New York, 1953.

Nadelson, Carol C. "The Pregnant Teenager: Problems of Choice in a Developmental Framework", Psychiatric Opinion. Vol. 12, No. 2, February 1975.

Notman, Malkah T. "Teenage Pregnancy: The Nonuse of Contraception", Psychiatric Opinion. Vol. 12, No. 2, February 1975.

Oberst, Byron B. "Adolescents and Some of Their Social Problems, Including Adulthood", Nebraska SMJ. September 1970.

Pollack, Ronald Irwin. "An Examination of Selected Vocational Behaviors of 12th Grade School Age Pregnant Girls", Dissertations Abstracts Internationa1. Vo1. 37, May 1977, pp. 6957-6958.

Wattenberg, William W. The Adolescent Years. Harcourt, Brare, and World Inc., New York, 1955. 